\title{
A Permanência de Mulheres em Situações de Violência: Considerações de Psicólogas
}

\author{
Madge Porto ${ }^{1}$ \\ Universidade Federal do Acre \\ Júlia S. N. F Bucher-Maluschke \\ Universidade de Brasília
}

\begin{abstract}
RESUMO - O objetivo desse artigo é identificar o que pensam psicólogas que atendem ou atenderam mulheres em situação de violência doméstica/conjugal, e as motivações para a permanência de algumas delas nessas situações. A proposta metodológica é um estudo qualitativo, utilizando-se entrevistas semiestruturadas e análise de conteúdo. Os resultados apontam como motivação para as mulheres permanecerem em situação de violência: a força do patriarcado; as marcas identitárias do amor romântico e os ganhos secundários das mulheres na experiência vivida. Esses resultados confirmam em parte estudos anteriores, porém, algo novo se destaca. Ao contrário do que apresentam alguns estudos, as psicólogas consideram a determinação sociocultural do fenômeno da violência contra as mulheres na construção do sofrimento psíquico e da intervenção proposta.
\end{abstract}

Palavras-chave:violência contra as mulheres, gênero, psicólogas

\section{The Permanence of Women in Situations of Violence: Considerations for Psychologists}

\begin{abstract}
The aim of this paper is to identify what psychologists think who attend women in situations of domestic / marital violence, about the reasons for the persistence of some of the women in these situations.In this study qualitative research methods were used including semi-structured interviews and content analysis. The results show the following motivations for women to stay in violent situations: the strength of patriarchy; the identifying marks of romantic loveand secondary gains of women in the lived experience. These results partially confirm previous studies, but something new stands out. In contrast to what some studies have pointed out,psychologists consider the determination of the sociocultural phenomenon of violence against women in the construction of psychological distress and the proposed intervention.
\end{abstract}

Keywords:violence against women, gender, psychologists

Depois de algum tempo de ativismo feminista, de pesquisa sobre o fenômeno da violência contra as mulheres e do trabalho com políticas públicas para essas mulheres, uma questão passou a se destacar: por que algumas mulheres persistem em relações mediadas pela violência? Mesmo depois da implantação de uma rede de enfrentamento à violência contra as mulheres (delegacias da mulher, casasabrigo, centros de referência) pelo governo federal, além da Lei Maria da Penha (Lei 11.340/2006) (Brasil, 2006c), algumas mulheres continuam vivendo relações conjugais mediadas pela violência. Nesse contexto é importante considerar que há muitas diferenças entre essas mulheres: etnia, classe, cor, instrução, que fazem a violência se expressar de diferentes formas e magnitudes, mas não faz com que alguma delas esteja livre de sofrer violência.

Outra questão relevante nesse contexto é que as políticas públicas para as mulheres em situação de violência apresentam as ações em psicologia como fundamentais na operacionalização dessa política específica. (Brasil, 2003, 2005a, 2005b, 2006a, 2006b).

Diante disso, se faz necessário pensar sobre esse fenômeno. Assim, o objetivo deste artigo é identificar o que

1 Endereço para Correspondência: Universidade Federal do Acre, Próreitoria de Assuntos Estudantis, PROAES, Distrito Industrial, Rio Branco, AC, Brasil, CEP: 69920900.E-mail: madgeporto@gmail.com pensam psicólogas que atendem ou atenderam mulheres em situação de violência quanto às motivações para a permanência de um número significativo de mulheres em situações de violência doméstica/conjugal, como destaca Garcia, Ribeiro, Jorge, Pereira e Resende (2008).

Para a discussão do fenômeno da violência contra as mulheres faz-se necessário utilizar a categoria de análise gênero. Considerando que a discussão sobre o conceito de gênero é extensa e complexa, e conta com a contribuição mais recente de autores/as como Rubin (1993), Butler (1990, 1992), Bourdieu (1998/2005), Swain (2006), Arán (2009), Lago (n.d.) entre outras/os, se faz necessário definir a partir de qual referência o problema em questão será analisado. Assim, neste estudo, as reflexões terão como base as discussões propostas por Butler (1990), Arán (2009), Lago (n.d.) e Swain (2006), que discutem a questão a partir do que se denomina a terceira onda do feminismo (Lago, n.d.).

Butler (1990) apresenta a categoria sexo como uma produção discursiva do gênero questionando o binarismo sexo-gênero que coloca o sexo no lugar da natureza. Swain (2006) discute sobre o dispositivo amoroso, que impõem às mulheres o desejo do amor romântico e está ligado à construção social do feminino na cultura patriarcal. Esses conceitos são importantes para possibilitar uma reflexão sobre o fenômeno da permanência de mulheres em situações de violência, para além de uma discussão que se fundamenta 
numa concepção de gênero que, de alguma forma, reforça uma naturalização, um binarismo: sexo versus gênero. Além disso, podem se articular com o conceito de masoquismo da psicanálise, por se referirem aos discursos que constituem subjetividades. Dessa forma, a análise do tema, a partir da articulação desses conceitos, pode contribuir para a ampliação da discussão considerando a complexidade do fenômeno.

Assim, no que se refere ao conceito de masoquismo, pode-se destacar que Freud (1924/2007; 1919/2000b) não descreve o masoquismo como algo da essência feminina, pois destaca que: "Quando se examina melhor algumas das fantasias masoquistas que receberam uma elaboração psíquica [Verarbeitung] mais rica, constata-se, de maneira nítida, que a pessoa foi colocada em uma situação típica da condição feminina (...)" (Freud, 2007/1924, p.108). Dessa forma, Freud não restringiu o masoquismo à mulher e sim a quem ocupa uma posição que culturalmente é definida para as mulheres. "A transformação do sadismo em masoquismo parece dever-se à influência do sentimento de culpa que participa do ato da repressão" (Freud, 1919/2000b, s/p), e, assim, não há como existir sentimento de culpa fora de uma referência sociocultural, e, no caso das mulheres, a exacerbação dessa culpa é constituída numa cultura patriarcal, construída na relação com a cultura. Freud ainda esclarece que:

Com a finalidade de tornar mais fácil seguir essas transformações na fantasia de espancamento, devo arriscar-me agora a restringir as minhas descrições a casos femininos, os quais, sendo quatro contra dois, constitui de qualquer modo a maior parte do meu material $(1919 / 2000 b, \mathrm{~s} / \mathrm{p})$.

Os casos que Freud analisou foram quatro de mulheres contra dois casos de homens. O que já aponta que não é algo de uma pretensa "natureza" feminina.

Para Kehl (2008) a psicanálise esclarece que o sujeito da psicanálise é sempre ser de linguagem, ou seja, de cultura, apesar das tentativas de Freud de estabelecer a natureza da sexualidade. A autora destaca que isso não é nenhuma novidade, está posto na teoria psicanalítica "previsto em Freud e explicitada por Lacan" (Kehl, 2008, p. 254). A cultura designa o feminino e o masculino e isso não se estabelece vinculado a uma base biológica.

Neri (2002) ressalta que a psicanálise prestou atenção no discurso feminino, quando deu ouvidos à histeria. Para a autora, ocorreu algo inédito no pensamento ocidental, já que "um outro", "um feminino" é apresentado depois de séculos de exclusão. Todavia, ela destaca que mesmo esse movimento de "dar voz a esse outro, singular" (Neri, 2002, p. 13) reafirma o masculino como universal. Discussão também levantada por Kehl (2008) e por Arán (2009). Nesse ponto, Arán (2009) refere: “(...) é necessário desconstruir a lógica falocêntrica para que surja uma economia subjetiva e libidinal feminina" (p. 662).

Laurent (2012), por sua vez, aborda os pressupostos psicanalíticos e a escolha das mulheres, e destaca as questões do feminino discutindo o "masoquismo feminino" do ponto de vista de Freud e Lacan, considerando o movimento feminista uma ação contra uma ordem patriarcal, a partir da produção das psicanalistas mulheres e destacando que Lacan questiona Freud no entendimento do masoquismo como algo da "natureza feminina": “(...) é claro que Lacan aborda os fenômenos que foram reagrupados sob a rubrica 'masoquismo feminino', mas faz um esclarecimento com a ajuda de outros conceitos, recusando o de masoquismo feminino." (Laurent, 2012, p. 53).

Assim, mesmo que, segundo Lago (s/d) a psicanálise e o feminismo se articulem em relações marcadas por desencontros, parece ser possível observar mais semelhanças que confrontos entre a psicanálise e o conceito de gênero, pois para a psicanálise o sujeito só se constitui na relação com o outro que representa a cultura (Freud, 1938/2000, 1921/2000). Dessa forma, não é possível falar-se de algo da subjetividade sem considerar a cultura, as construções do que são "mulher" e "homem" estabelecidos.

\section{O movimento feminista, as mulheres que sofrem violência e as políticas públicas}

O movimento feminista promoveu a construção de políticas de inclusão e valorização das mulheres ao longo do século XX. Nessa trajetória, as feministas obtiveram conquistas importantes na Constituição de 1988 e na efetivação das primeiras políticas públicas para as mulheres, por exemplo, as delegacias especializadas de atendimento à mulher (DEAM) e o programa de atenção integral à saúde da mulher (PAISM) (Pinto, 2003). Conquistas que continuaram na década de 1990 com as casas-abrigo e, mais recentemente, com os centros de referência.

Percebe-se, dessa forma, um percurso que pretende oferecer às mulheres que sofrem violência oportunidade de romper com essa vivência, apesar das dificuldades na implantação de tais políticas públicas. Contudo, mesmo com esses espaços constituídos e preparados para levar a mulher a se conscientizar de sua situação de submissão e romper com a situação de violência vivida, em um número significativo de casos, isso não acontece, pois são recorrentes as reconciliações (Brandão, 1998; Garcia et al., 2008).

Alguns poucos estudos (Hanada, D’Oliveira, \& Schraiber, 2008, 2010; Conselho Federal de Psicologia - CFP, 2008, 2010) apresentam o foco no atendimento psicológico que é realizado nas políticas especializadas. No estudo de Hanada et al. $(2008,2010)$ há a avaliação das pesquisadoras sobre o trabalho desenvolvido pelas psicólogas nas políticas de enfrentamento à violência contra as mulheres no estado de São Paulo e a conclusão é que o trabalho realizado não contribui para o empoderamento ou empowerment das mulheres atendidas. Já no estudo do CFP $(2008,2010)$ há uma descrição quantitativa e qualitativa de como essas profissionais realizam o trabalho e quais as suas características. A maioria das(os) psicólogas(os) que responderam ao questionário do Centro de Referência Técnica em psicologia e Políticas Públicas - Crepop atua no Sudeste, em instituições públicas, com 30 horas semanais de trabalho e com remuneração de até $\mathrm{R} \$ 1.500,00$ (mil e quinhentos reais). Todavia, alguns dados chamam a atenção: $42,5 \%$ apontam o Direito como área que influencia fortemente sua atuação entre respostas como Saúde Mental, Saúde Pública e Psicanálise; 79,6\% refere que a 
atividade mais frequente em sua prática é o acolhimento e o aconselhamento entre respostas como assistência/tratamento psicológico (67\%) e supervisão psicológica (18,4\%) (CFP, 2008). Em ambos os estudos há uma ideia que a intervenção em psicologia é limitada ou mesmo inadequada para o tipo de serviço, sendo defendida uma intervenção que não tenha foco no sofrimento psíquico e sim na situação social da mulher.

O estudo de Garcia et al. (2008) observou que aproximadamente $34 \%$ das mulheres que buscaram unidades de saúde, de segurança pública e serviços especializados de atendimento à mulher em situação de violência, voltaram a viver com o homem agressor com a esperança de melhorar o relacionamento conjugal.

Diante desse resultado, e considerando que a psicologia tem um lugar relevante nessa política pública, é que se justifica investigar como psicólogas que atendem essas mulheres entendem as motivações para a permanência de algumas dessas mulheres em situações de violência, em um contexto ainda não estudado.

\section{Método}

Considerando que o objetivo desse estudo é conhecer como é significada a permanência de algumas mulheres em situações mediadas pela violência na experiência do atendimento psicológico de psicólogas(os) que cuidam da saúde mental dessas mulheres no estado do Acre, a proposta metodológica definida foi de um estudo exploratório, descritivo e qualitativo, dada a escassez de referências bibliográficas que tratem especificamente do atendimento psicológico às mulheres em situação de violência. Para tal foi decido utilizar a entrevista semiestruturada ${ }^{1}$ presencial como técnica para a investigação, após os resultados de um estudo inicial através de um questionário online ${ }^{2}$.

As psicólogas inscritas no CRP 20 seção Acre (CFP, 2011) foram convidadas a participar da entrevista a partir de um convite via mensagem eletrônica. Tinha-se como objetivo entrevistar psicólogas que atendem ou atenderam na rede de enfrentamento à violência contra as mulheres e psicólogas

1 A entrevista foi dividida em três partes. A parte inicial investigou temas como a forma de identificação do caso de violência, a intervenção realizada, o que conhece dos documentos da Secretaria de Política para as Mulheres - SPM, como viveu a experiência, quais as teorias indicadas para essa intervenção, como compreende o fenômeno da violência contra as mulheres e como explicam as situações em que as mulheres mesmo após receber apoio continuam nas situações mediadas pela violência. Também tinha questões sobre o resultado e a avaliação da eficácia, dificuldades e facilidades para o atendimento psicológico. Por fim, o papel que o psicólogo/a tem/teve na equipe multiprofissional. Ainda foi aplicada uma escala onde a psicóloga avaliava seu grau de concordância com as orientações referentes ao atendimento psicológico que foram retiradas dos manuais, portarias e termos de referência da SPM e, por fim, a aplicação de um questionário fechado para a definição de um perfil sociodemográfico e de formação em psicologia da informante. Vale destacar que o estudo realizado é mais amplo do que os resultados ora apresentados nesse artigo. Os demais resultados estão sendo publicados em partes, constituindo outros artigos.

2 O projeto de pesquisa foi aprovado pelo Comitê de Ética em Pesquisa com Seres Humanos da Universidade Federal do Acre em 13.10.2010, protocolo $\mathrm{n}^{\mathrm{o}} 23107.014891 / 2010-79$. que não tinham essa experiência de forma que pudesse haver uma comparação entre as respostas dos dois grupos.

Das 31 psicólogas convidadas, 15 manifestaram o desejo em participar como voluntária de pesquisa, mas só 12 efetivaram a participação. Assim, foram realizadas 12 entrevistas de fevereiro a março de 2012, sendo seis com psicólogas que tinham experiência em serviços da rede de enfrentamento à violência contra as mulheres, em especial o centro de referência e a casa-abrigo e seis com psicólogas que nunca fizeram atendimento em serviço especializado, mas que já atenderam ou atendem mulheres em situação de violência. Por fim, desse último grupo, uma psicóloga teve experiência de atendimento com meninas em situação de conflito com a lei e outra, por não ter ainda a psicóloga para atender no serviço especializado para mulheres em situação de violência, quando foi solicitada, realizou alguns atendimentos.

As entrevistas foram transcritas e analisadas a partir do método de Análise de Conteúdo (Bardin, 1977/1997) onde foram identificadas várias categorias e nesse artigo serão apresentadas as categorias referentes à compreensão que as psicólogas informantes têm sobre a permanência de algumas mulheres em situações de violência. Vale destacar que os nomes apresentados para identificar as psicólogas são fictícios para garantir o anonimato das informantes e nos trechos escolhidos para ilustrar a categoria de análise foram retirados os vícios de linguagem como "né" e "tá", a pedido das informantes e sem prejuízo da ideia desenvolvida nas falas das entrevistadas.

\section{Resultado e Discussão}

As psicólogas entrevistadas têm idades variadas, tendo a mais jovem 21 anos e a mais velha 67 anos. A maioria fica na faixa etária entre os 30 e 39 anos. A maior parte não tem companheiro/a. Metade do grupo declara não ter religião, as que declaram são religiões cristãs e $1 / 3$ do total não nasceu na cidade na qual realiza seu trabalho. A maioria tem pósgraduação, nenhuma tem o título de especialista do Conselho Federal de Psicologia - CFP. Mais da metade trabalha mais de 30 horas semanais. A maioria tem mais de um vínculo de trabalho. Apenas uma tem filiação a partido político e outra é ativista em movimentos sociais. Apenas três não são funcionárias públicas e apenas uma ganha até $\mathrm{R} \$ 1500,00$ (mil e quinhentos reais) e oito mais de $\mathrm{R} \$ 3.000,00$ (três mil reais).

Das seis informantes que trabalharam em serviços especializados duas em centro de referência, duas em casaabrigo e duas trabalharam em ambos os serviços. Das seis que não trabalham nem trabalharam em serviços especializados, três trabalham em consultório particular, sendo que destas, duas realizam outras atividades; duas trabalham em hospital e uma em uma unidade básica de saúde.

Quanto à teoria psicológica utilizada em sua atividade profissional, sete referiram a teoria psicanalítica; uma referiu a abordagem psicodinâmica orientada para o insight e Gestalt-terapia; uma referiu psicologia social, da saúde e análise do comportamento - Cognitivo comportamental; três a "Linha Humanista", sendo que uma especifica "Abordagem 
Centrada na Pessoa”, outra, apesar de não deixar clara a teoria com que trabalha, fala de "Atendimento direto, aqui e agora".

É importante apontar que o processo de inserção das psicólogas como servidoras públicas, no grupo estudado, ocorre em meio a uma pressão pelo ajustamento segundo as normas de um contrato de trabalho. Este contrato, na maioria dos casos, apresenta explicitamente nas atribuições do cargo, mas também, de modo subliminar, expectativas sobre o trabalho em psicologia, muitas vezes, irreais, como por exemplo, que com apenas uma conversa a psicóloga teria condições de promover as mudanças que são esperadas pelos serviços nas mulheres atendidas, ou que a psicóloga precisa convencer as mulheres a lutar por seus direitos.

Sete psicólogas utilizam explicitamente o conceito de gênero quando falam do fenômeno da violência contra as mulheres, as demais não o utilizam, mas todas consideram os papéis desempenhados por homens e mulheres como algo culturalmente determinado quando se referem ao machismo, patriarcado ou "estereótipos sociais" (como foi referido pela entrevistada Ariadne). Vale destacar que essa questão não está relacionada com o grupo ao qual a psicóloga foi classificada, pois das que não utilizaram explicitamente o conceito de gênero, duas são do grupo das que tem experiência de atendimento nos serviços especializados, destacando que são exatamente as duas que referem utilizar em suas intervenções abordagens humanistas.

Isso aponta que as psicólogas, independente de onde realizam seu trabalho e da teoria psicológica utilizada, compreendem o sofrimento psíquico de forma integrada às questões sociais, não havendo uma compreensão limitada às questões pessoais vivenciadas pela mulher atendida, e sim uma compreensão da influência dos aspectos sociais e culturais na produção daquele sofrimento e na possibilidade de sua superação. Sem com isso desconsiderar que o foco do trabalho precisa ser a subjetividade.

\footnotetext{
Então, tem toda uma carga social e pejorativa em relação a isso. Então é... Eu acho, assim, que quando fala que ela permanece nessa situação é desejando algo desse outro, mas que esse outro não dá, mas que de certa forma, assim, é... A questão do abandono, de está sozinho. Tudo isso influencia. (...) Dessa questão social mesmo, dessa formação dessa sociedade que a gente... Que a gente vive. E ai eu fico pensando assim é... Como é alto o preço que algumas mulheres têm que pagar por é... mudarem esses conceitos. (Xena)
}

Por fim, é importante destacar que não houve diferenças na forma de perceber as motivações para a permanência em situação de violência quando comparado os dois grupos.

\section{Por que as mulheres continuam em situação de violência? O que dizem as psicólogas do Acre}

Há várias motivações para as mulheres permanecerem em situações de violência, explicações estas que também estão fundadas na referência teórica utilizada pela psicóloga. A análise de conteúdo das entrevistas, a partir dos temas (Franco, 2008) referidos pelas informantes sobre as motivações para as mulheres permanecerem em situação de violência, promoveu o estabelecimento de três categorias: Categoria 1 - Força do patriarcado e a busca de um salvador: "um homem pra chamar de seu?"3; Categoria 2 - Sonhos do amor romântico; Categoria 3 - Ganhos secundários: o preço para realizar um desejo.

\section{Categoria 1 - Força do patriarcado e a busca de um salvador: "um homem pra chamar de seu?"}

(...) eu já escutei tantos relatos de culpa, de autopunição. (...) Ele bateu, porque eu mereci. Eu não fiz a comida na hora certa ou eu não sei ser uma boa esposa. (...)em alguns casos seria muito mais a tentativa de se encaixar dentro de um padrão do que é ser mulher (...) se sentir aceita. Se sentir aceita, principalmente dentro da religião. Acho muitas quando tem a religião muito forte, a questão da submissão que é... Acreditam que elas têm que aprender a ser submissas, aprender a aceitar aquilo que e imposto, aquilo que é... Que é colocado. (Malva)

Cunha (2007) apresenta também, como resultado de seu estudo, que há uma pressão familiar e instituições patriarcais que se manifestam de forma a promover a manutenção do casamento principalmente por conta dos filhos/as, pois esse seria o papel das mulheres.

Fica evidente a influência dos papéis de gênero definidos pelo patriarcado "Eu penso que ela vai tá se anulando, entendeu? Por outras questões, pelos filhos, pela sociedade, pela própria, como a gente colocou antes, pelos próprios valores, entendeu?" (Nora)

Algumas psicólogas destacam a dependência financeira que se mistura com a dependência emocional, mas sem esclarecer o que exatamente seria essa 'dependência emocional'.

Todas, é... de uma falta de... É um vazio das relações, dos sentimentos, sabe? (...) o que quê, o que quê tá por trás dessa mulher, que tem uma fortaleza imensa e se permite ser tão, tão fragilizada, se permite ser anulada? (...)Racionalmente, elas dizem que querem mudar, que quer sair dessa situação. Eé uma situação realmente de desconforto, porque quando a pessoa diz, assim: Não, ela não sai porque ela não quer. Não! Não é porque ela não quer. Ela não tem condição de. Ela não tem ainda força suficiente. Ela não percebeu que ela tem a força pra isso. Então é um aprender. (...)A gente teve casos aqui que não é o único, (...) assim, que a pessoa até, ela muda de relacionamento, mas ela procura um companheiro com comportamento semelhante. Então ela aprendeu a se relacionar daquela forma. (...) Tinham um sonho de encontrar alguém e que a coisa ia mudar. A coisa não muda. (...) Muitas têm que voltar realmente mesmo pro agressor pela questão às vezes até da dependência econômica.

3 Mesmo Que Seja Eu. (Autor: Erasmo Carlos) - Sei que você fez os seus castelos/E sonhou ser salva do dragão/Desilusão meu bem/Quando acordou estava sem ninguém/Sozinha no silêncio do seu quarto/Procura a espada do seu salvador/ Que no sonho se desespera/ Jamais vai poder livrar você da fera da solidão com a força do meu canto/ Esquento o seu quarto pra secar seu pranto/ Aumenta o rádio me dê a mão/ Filosofia é poesia é o que dizia a minha vó/ Antes mal acompanhada do que só/ Você precisa de um homem pra chamar de seu Mesmo que esse homem seja eu/Um homem prá chamar de seu. 
(...) Mas eu não vejo como sendo o fator principal de tudo essa questão só econômica. Pesa, isso tem um peso, mas tem essa coisa da dependência do emocional, de tá com alguém. Precisa está com alguém. (...) É como se precisasse de fato... Terem que ter alguém pra ser mulher, terem que tá com a figura de um homem (...). (Açucena)

Cunha (2007) refere que as mulheres classificadas em seu estudo como em dependência emocional do companheiro seriam aquelas sem capacidade de agir, que cedem a chantagem, sentem medo (mesmo quando não saibam a causa do medo), culpa, vergonha e raiva e que sofrem com a possibilidade de ficarem sozinhas. A autora também destaca que algumas mulheres justificam a violência numa forma de proteger o agressor e a relação.

Chama a atenção, ainda, que a questão da dependência financeira não se restringe às mulheres sem condições de autonomia econômica. É algo que também é vivenciado por mulheres de estrato social mais abastado. Questão estudada por Cunha (2007) e definida como dependência econômica.

Estaria, então, essa dependência emocional nomeando “(...) a busca de um objeto idealizado que deve ser escolhido como único e insubstituível, contendo a promessa de plenitude e felicidade" (Haddad, 2009, p. 122)? Se for isso, este também pode ser considerado um movimento de tentativa de recuperação do narcisismo infantil marcando a formação de ideias que se busca insistentemente, ou, também poderia ser uma necessidade de adequação as referências do dispositivo amoroso (Swain) ${ }^{4}$.

(...) às vezes não tem condições objetivas de vida pra se manter com a sua prole junto, sem o companheiro. (...)há um sentimento, há um gostar, há uma coisa de tá no lugar ali do algoz, naquele lugar de vitima daquele algoz, (...) há uma dependência emocional muito grande eu penso, mesmo em mulheres que tem uma condição de se emancipar financeiramente. (...) na classe favorecida eu acho que tem essa questão também dos interesses, às vezes a perda, sei lá, o ônus vai ser maior que o bônus, bem maior que o bônus se ela separar por conta de cair padrão de vida também porque esse tipo de violência ela é mais sutil, ela é mais escondida, não é tão frequente. Bem ou mal as pessoas ainda tentam se preservar porque tem um nome(...). (Gardênia)

Cunha (2007) afirma que mulheres de classes média e alta têm mais dificuldade de terminar o casamento. Ao contrário do que poderia se esperar, pois teriam, em tese, mais condição financeira de separar de parceiros violentos.

As motivações de algumas mulheres, como: ser respeitável na sociedade, ser casada, ter um lugar de destaque na estratificação social ou manter a felicidade dos filhos, também não são suficientes para explicar porque se deixam desprezar e acreditam que assim poderão mudar o marido. Por outro lado, o homem também é percebido como o salvador:

4 O dispositivo amoroso se afirma nas práticas que se desdobram de forma exponencial para a construção do feminino: a educação formal, a pedagogia sexual, a disciplina dos corpos - magros e belos - a domesticação dos sentidos e dos desejos para seguir a imagem ideal da mulher. Isto é o sujeitamento, em sua plenitude (Swain, 2006, p. 12).
Aquele homem agressor que ao mesmo tempo é o agressor, éo que maltrata, é o que desqualifica a mulher. Você não serve pra nada. Se eu te deixar ninguém mais vai te querer. Você pensa que alguém vai te querer? Nossa isso aqui eu ouço tanto. Ao mesmo tempo que esse agressor muitas mulheres o enxergam como a única tábua de salvação. É como se tivesse no meio de uma, de uma enxurrada. O homem é aquele gravetinho que não dá segurança nenhuma no meu olhar, mas a mulher se agarra a ele como se fosse, como se ele fosse a tábua de salvação. (Malena)

Cunha (2007) identifica "a mulher como alteridade" (p.163), aquela que permanece na relação porque ter um homem em casa, mesmo sendo agredida, é estar protegida da violência de estranhos e é uma forma de ter status.

\section{Categoria 2 - Sonhos do amor romântico}

Gardênia refere que há uma confusão entre amor e ciúmes. Essa confusão, pode-se pensar, foi construída pelo amor romântico, constituição do 'amar' em nossa sociedade.

\begin{abstract}
Acho que também tem essa questão do envolvimento afetivo, as pessoas ainda confundem essa coisa do amor com a obsessão do cara. A gente já sabe que um dos indicios de violência no começo da relação é o cara já começar a ser muito controlador, ciumento, e as mulheres ainda veem isso como sinal de paixão, de amor, que ele tá cuidando, que ele gosta dela. Então, no começo elas não reconhecem esses sinais, e ai ficam cada dia mais envolvidas, e ai fica mais complicado depois quando acontece a primeira crise, porque já há um envolvimento maior, mas eu acho que ainda falta talvez reconhecer melhor esse sinais do agressor e também dela. Por que ela continua nesse mesmo lugar ainda? Ainda não discriminou, repetindo de novo com o agressor? (Gardênia)
\end{abstract}

O amor romântico se apresenta ainda como ideal de relacionamento amoroso continua presente mesmo diante das profundas mudanças no cenário contemporâneo como individualismo, marca principal dessa transformação (Costa, 1998; Goldenberg, 2004). O que estabelece uma tensão entre ideias que se apresentam contraditórias: a completude do amor romântico e a liberdade do individualismo moderno.

Haddad (2009) refere: "A fidelidade, portanto, articulase com o amor e funda a necessidade de se sentir amado, reconhecido e valorizado de forma exclusiva" (p. 100).

Há também a compreensão que as mulheres querem se mostrar fortes, como Brandão (1998) constatou, entendem ciúmes como amor, e, assim, quando resistem às mudanças, estão buscando uma forma de realizar a promessa romântica, a realização desse desejo.

Mas, é como se ela tivesse ali provando que ele não vai vencer ela daquela maneira, com a violência. (...) Porque eu já ouvi situações assim, da mulher dizer ele vai me bater, eu vou apanhar, mas não vai ser assim que ele vai me vencer. Toda vez que ele me bater eu vou me levantar no outro dia mais forte. (...) ela tá querendo provar pra ele que aquela metodologia dele, digamos, tá errada. (...) (Jasmine) 
Haddad (2009) apresenta em sua análise que dentro do imaginário do amor romântico “(...) o verdadeiro amor exigia sacrifícios e renúncias..." (p. 28). Algo do extremo do estado de estar amando, descrito por Freud (1921/2000) como estado de fascinação ou servidão. Nesses casos, tudo que é feito e demandado pelo objeto de amor é aceito e legítimo. Birman (2006) destaca que "O sujeito oferece ao outro o seu corpo e o seu psiquismo para que aquele possa gozar como queira, desde que, em contrapartida, ele lhe ofereça proteção para o desamparo (...) pacto masoquista, realizado à custa de uma imensa humilhação da autoestima" (p. 52). De alguma forma, é possível que essa servidão esteja presente nesses casos de relações mediadas pela violência. Talvez também seja isso que motive algumas mulheres na permanência desses relacionamentos.

Outra questão importante que se destaca é a noção de autoestima, argumento recorrente no contexto das intervenções para mulheres em situação de violência (Brasil, 2003, 2005a, 2005b, 2006b) e, em especial, o que seria uma autoestima alta. Da perspectiva dos conceitos gênero e dispositivo amoroso (Butler, 1990; Swain, 2006), o modelo social para uma mulher se considerar empoderada (sendo o empoderamento entendido a partir do referencial citado anteriormente) e plena passa por ser amada e aceita. Assim, a autoestima estaria em se enquadrar ao modelo? Ou romper com esse modelo traria uma autoestima? Mas qual seria? Diante dessa reflexão, qual autoestima se buscaria? Como ser empoderada num contexto que, a todo o momento, regula, sujeita e define?

Talvez, como refere Arán (2009):

"O grande desafio é afirmar a especificidade da experiência vivida, ou seja, a positividade do corpo feminino na sua diferença (...) esse gesto de positivação da feminilidade teria longo alcance como crítica da cultura e forma de enunciação de novas subjetividades". (p. 663).

Para as psicólogas, o movimento de permanecer em relações mediadas pela violência também é determinado por um desejo de mudança do homem, marido ou companheiro: "É de que o companheiro mude mesmo. Ela na verdade não quer romper a relação não, a não ser que ela já tenha vivido... Já tenha sido muito machucada mesmo e quer romper (...)" (Gardênia).

Pode-se refletir sobre esse argumento a partir do conceito de dispositivo amoroso "O amor está para as mulheres o que o sexo está para os homens: necessidade, razão de viver, razão de ser, fundamento identitário." (Swain, 2006, p. 10). Essa discussão avança no sentido de apresentar, de forma mais direta, que tudo que se refere a mulheres e homens são construções sociais, que não há nada "natural", nem mesmo o sexo, aqui se valendo do conceito de Foucault (1988) de dispositivo de sexualidade, que discorre sobre a "[...] produção discursiva do sexo-necessidade, do sexo-verdade, do sexo-identidade, do sexo-vida" (Swain, 2006, p. 5). Swain (2006) apresenta ainda que o dispositivo amoroso constrói o que é o feminino, se afirmando em práticas cotidianas da educação e da disciplina.
Cunha (2007) apresenta em seu estudo as motivações de mulheres em relações heterossexuais permanecerem em situação de violência conjugal a partir da escuta de 17 mulheres de camadas médias e altas de "(...) uma cidade brasileira de porte médio" (p.19). Além de dependência emocional e econômica, citadas anteriormente a autora destaca que algumas mulheres acreditam "(...) no velho sonho transformador do amor." (p.162) e acreditam que esse sentimento, que segundo a autora as mulheres nomeiam "amor", fará o parceiro mudar, de forma a transformá-lo no homem que elas desejam. Essas mulheres foram denominadas pela autora como "Mulheres onipotentes" (p.162).

Freud (1914/2000), quando fala sobre o narcisismo de homens e mulheres refere que, entre as mulheres, a necessidade é de ser amada e não de amar. As mulheres dirigiriam uma parte de sua libido para si, o mesmo não aconteceria com os homens. Nesse ponto, poder-se-ia perguntar se as mulheres que insistem em viver situações de violência conjugal fazem isso não porque amam o homem, do qual se compadece ou porque deseja mudá-lo, mas o que desejam é serem amadas, sendo assim uma atitude narcisista. Como se não admitissem perder o lugar que antes ocupara de ser amada e desejada plenamente. Todavia, a estratégia utilizada para retomar esse amor é se degradando, se submetendo à violência e ao desprezo. Do ponto de vista das discussões feministas contemporâneas da psicanálise (Arán, 2009), uma lógica falocêntrica, de negativação do feminino, que se constitui a partir da exclusão, sendo esse lugar fruto de contingências históricas e políticas.

Ariadne reflete sobre a ilusão que é alimentada pelas mulheres:

Eu me lembro... Mamãe... quando eu era pequena, eu achava muito engraçado, mamãe dizia assim (...) Eu fico tão chateada quando destroem as minhas ilusões. (Risos) - Mas, mamãe, as ilusões não são pra serem destruídas mesmo? - Não, a gente tem que saber cultivar as ilusões da gente. Eu ficava, assim, mas como é que pode? Quer dizer, se é ilusão, o próprio nome tá dizendo. Isso é ilusão, é pra ser destruida. Mas ela ficava, ficava ofendida com quem queria mexer com as ilusões dela (...) Ela falava com clareza: As minhas ilusões eu quero mantê-las. (...) o que mais iria explicar essa satisfação substitutiva que tem aí? De você... A qualquer momento eu chego lá. Não cheguei dessa vez, mas vai ser da próxima, talvez com mais sacrificio, com mais coisas, como essa senhora [uma mulher que atendeu] que é muito inteligente, (...) Ela fala: Oh! Meu Deus quanto tempo, quanto sapo eu engoli tentando encontrar uma solução, tentando descobrir porque caminho eu tocava o coração desse homem? Não consegui (...) ele não quer, ele tá noutra não adianta eu ai, insistir, insisti a minha vida inteira (...) (Ariadne).

Para sair da situação será preciso destruir as ilusões? Abandonar o sonho inicial formado, moldado pelas referências do amor romântico? E como lidar com as pressões do cotidiano para esse enquadramento?

Haddad (2009), a partir dos textos Freudianos, destaca que leva em conta a evolução dos conceitos da psicanálise ao longo de sua história e afirma: "A busca do amor incondicional guarda o desejo de ser amado como um eterno 
presente de plenitude. É essa fantasia de completude que todos querem resgatar pelo viés do amor" (p.106).

As mulheres que sofrem violência se colocam como alguém que quer amar incondicionalmente, que quer realizar todos os desejos do marido. Contudo, pode-se pensar que, na realidade, essas mulheres desejam continuar sendo amadas como foram outrora. Poderíamos supor, assim, que não se trata de uma atitude altruísta e sim, paradoxalmente, narcisista, como referido anteriormente. Freud (1914/2000) afirma que o sentimento de inferioridade de um indivíduo é resultado de um "eu" empobrecido, que necessita do amor do outro para elevar sua autoestima. Dessa forma, pode-se deduzir que uma pessoa que esteja vivendo em situação de violência de forma sistemática e repetitiva submete-se a essa vivência por demandar o amor do outro a qualquer preço para não se fragilizar ainda mais.

Pode-se pensar que as mulheres que continuam em situação de violência, como no caso citado por Ariadne, estariam buscando satisfação por um caminho já conhecido e seguro, repetindo experiências antes vividas (Freud, 1919a/2000)? A fala abaixo parece deixar essa questão mais explícita:

(...) ele não quer mais ela, mas ela quer. (...) Normalmente elas relatam: - Ah, eu já perguntei, tu me ama? - Não, queria uma mulher melhor. Queria... E a pessoa tá lá convivendo com ele. Ou então ele sempre sai e deixa ela na casa sozinha tendo que lidar com tudo, todo o peso de uma mulher e ela tá lá ainda na mesma situação (...) (Violeta).

Essa reação poderia ser comparada a um estado em que o objeto foi introjetado no ego (Freud, 1921/2000), e que, sendo assim, o desprezo por si seria sim o desprezo pelo amado. Talvez por buscarem realizar o desejo do absoluto, como diz Ariadne "(...) é em busca desse absoluto. Quer dizer, se ele não é o homem que ela se idealizou, ela tem que ser uma mulher mágica que o transforme nesse homem idealizado". Contudo, essa é uma das explicações rechaçadas pelas feministas que entendem que dessa forma transforma-se uma questão social em psicológica.

É importante destacar que as mulheres são constituídas num dispositivo amoroso reafirmado cotidianamente pelas tecnologias de gênero (De Lauretis, 1987) que as levam a essa necessidade, da forma como esta é percebida, ou seja, tudo que fazem é por amor, submetem-se a diversas formas de violência por amor. Todavia, se considerarmos que esse desejo é constituído de múltiplas formas, cotidianamente, e que não é natural, o argumento que mulheres permanecem em situações de violência para terem um provedor ou um status social de mulher estabelecido como mais valorizado, não é suficiente, é preciso saber o que define essa valorização. Tendo o patriarcado definido uma psicanálise que representa o feminino pelo negativo e pela falta, pode-se pensar que continuar nessa situação seria uma forma de tentar conseguir realizar o desejo de ser amada e reconhecida.

\section{Categoria 3 - Ganhos secundários: o preço para realizar um desejo}

Ariadne destaca possíveis ganhos secundários que, talvez, justifiquem a dificuldade de mudar a si mesma e o desejo de querer mudar o parceiro:

Tem, a gente sabe que tem, os beneficios secundários até do sadomasoquismo ali da coisa. (...) Elas ficam presas na situação.

(...) A dependência financeira e emocional. Tem algumas que nem é a dependência financeira, é emocional mesmo. (Ariadne)

Aqui a psicóloga fala de algo que é ponto de tensão: a explicação a partir do conceito psicanalítico de masoquismo. É importante destacar que mesmo quando o objetivo é questionar o uso desse conceito há, quando se utiliza de forma adequada o conceito, a afirmação de que é possível utilizá-lo no entendimento do fenômeno.

Narvaz (2010), em um texto que pretende fazer uma critica, afirma que “... a subjetividade masoquista é uma forma possível de inscrições dos sujeitos na ordem da cultura" (p. 54) e que a subjetividade masoquista é construída/ determinada pela "história da produção ideológica das subjetividades em gênero" (Narvaz, 2010, p.55). Esses argumentos só afirmam que a discussão do masoquismo não se refere a uma suposta natureza feminina e, se a subjetividade masoquista existe entre mulheres que sofrem violência, é preciso fazer algo e não apenas dizer que essa é uma experiência tanto de homens quanto de mulheres, não sendo, assim, "natural" das mulheres. É importante destacar que os textos freudianos não afirmam a existência de uma essência feminina ou de uma natureza feminina masoquista, como a própria autora destaca. Contudo, isso não descarta que o masoquismo é algo que se apresenta também entre as mulheres e que, se esse tipo de servidão acontece entre essas mulheres que se sujeitam à violência, é preciso pensar formas de intervir considerando esse processo. Dessa forma, é possível trazer a psicanálise para a discussão da violência contra as mulheres, sem, com isso, naturalizar a violência e o lugar do feminino ou negar as teorias feministas de gênero, como fazem Arán (2009) e Lago (n.d.).

(...) é como se fosse assim: aprendi dessa forma. É ruim, mas, mas eu não gosto, mas eu não sei fazer de outra forma, não sei fazer de outra maneira. É assim, é assim. É como assim: Então eu vou, vou levando. Algumas mulheres, elas realmente percebem, elas têm uma consciência e realmente vão em busca, e se movimenta. Faz um movimento realmente pra, pra romper. Mas outras elas fazem o movimento, mas elas voltam, voltam. É um, um... Às vezes, até aquele ditado popular é ruim com ele, mas é pior eu ficar sem ele. Tem os filhos, tem, sabe. Por conta das crianças. E que muitas vezes esse próprio pai não é tão... Não é um pai significativo. (Açucena)

Cunha (2007) destaca que há um desejo a ser realizado quando uma mulher permanece em uma situação de violência, como se ela fizesse uma permuta, fica na situação de violência para evitar a solidão, não diminuir o nível de conforto a qual está acostumada (mulheres das classes sociais média e alta) e garantir o 'bem-estar' dos filhos/as. Mas faz questão de destacar que não há masoquismo, pois as mulheres não gostam de apanhar, como a permanência nessas situações faz supor. Refere que essa ideia se popularizou a partir da concepção freudiana “(...) que as mulheres tinham 
tendência a desejar a dor" (Cunha, 2007, p. 166). A autora ainda destaca que as mulheres que entrevistou não gostam, não desejam e não merecem ser agredidas, afirma que a mulher fica na situação de violência "porque não encontra saída para resolver aquela situação, naquele momento, ou porque depende emocionalmente daquele parceiro" (Cunha, 2007, p. 166). Com esse argumento a autora volta ao início de sua avaliação, com o argumento da dependência emocional, além de entender o masoquismo de forma leiga e não como Freud o entendia, ou seja, como algo que se constitui da fusão entre duas pulsões de forma que a sexualidade se une a uma destrutividade que se direciona para dentro do sujeito (Freud, 1930/2010, 1924/2007), sendo assim, não é uma questão de gostar ou de ter vontade de apanhar, mas sim realizar um desejo, pelo que as psicólogas entrevistadas relatam, o desejo de realizar a promessa do amor romântico.

É importante considerar essa questão, pois as psicólogas entrevistadas no Acre avaliam que existe um processo onde há algo que faz mulheres se sujeitarem à violência, e o conceito do masoquismo pode ser importante nesse processo. Masoquismo, dessa forma, entendido, segundo Menezes (2012), como uma forma de suportar a dor para tentar realizar um desejo, e não como prazer pela dor. Em outras palavras, como se valesse a pena sentir a dor para obter o que deseja.

As informantes também destacaram que as mulheres não querem pagar o preço de realizar uma mudança, abdicar de seu desejo, sendo melhor desejar a mudança do outro:

\begin{abstract}
Eu acho que não é que elas queiram continuar nessa relação (...) é que ela simplesmente não consegue encontrar o caminho pra sair. Bancar essa vida fora dessa relação, eu entendo que seja bancar algo completamente novo do qual ela não tem, não tem conhecimento nenhum. (...) É preciso bancar uma vida nova. E ai com tudo que vem junto, é fazer tudo diferente, morar numa casa diferente, não ter a presença daquela pessoa ali, não ter que lidar com aquela situação que é comum, vamos dizer assim, não é que seja boa, mas ela já sabe como lidar com aquilo. (...) Que não é só uma questão de estar sozinha ou livre da violência, mas é estar sozinha e livre da violência e com todo o resto. É ter que lidar com a vida de separada, com os filhos sem pai. (...) Então tem toda uma série de questões aí que vai dessa mulher saber que pode enfrentar essa situação. (Serena)
\end{abstract}

Por fim, outro ponto que é destacado para justificar a permanência nas relações mediadas pela violência é a revitimização que as mulheres sofrem quando procuram a rede de enfrentamento à violência contra as mulheres, como as que retornam ao sistema várias vezes: "Há outras que também já passaram pela primeira... Pelo meu primeiro atendimento, mas que já tiveram outros... Chegaram aqui em 2007, tiveram aqui em 2009, tiveram aqui em 2010." (Açucena).

Demonstrando com isso que o problema não foi devidamente resolvido. Essa problemática pode estar associada à seguinte questão: como o trabalho está sendo desenvolvido para obter o fim desejado de forma que a mulher deixe de viver situações de violência familiar, conjugal, doméstica e/ou de gênero? A rede de atendimento, assim, apresenta-se inoperante e lenta e não funciona como o esperado.
É importante destacar um ponto: a diferença de objetivos entre a intervenção psicológica e do direito, mesmo dentro da política pública específica. Na expectativa de fazer cumprir a lei, questão muito importante no contexto do processo de coibir a violência contra as mulheres, há uma expectativa do direito dirigida à psicologia desta ser colaboradora nas demandas que lhe são prerrogativas. E isso parece ter causado parte dessa mistura, dificuldade de delimitação das ações nas políticas especializadas.

O judiciário, e talvez as instituições da rede, com o objetivo de punir o agressor a partir da visão vítima versus agressor, tem uma atenção maior nessa questão - que é relevante, mas não pode e não deve ser das psicólogas. Assim, a forma de trabalho dessas instâncias, como por exemplo, de inquérito ou de relato repetitivo "dos fatos", passa a ser demandado também para a/o psicóloga/o que nesse contexto deveria ser a profissional que tem a função de ouvir, acolher a dor da mulher, seu sofrimento psíquico, ouvindo suas dúvidas, suas frustrações, seus desejos e suas contradições.

\begin{abstract}
Eu nunca começo um, um atendimento sobre o fato, sobre o que aconteceu. Eu não faço essa pergunta, sabe. Eu quero saber sobre a pessoa. Como é que ela está. Quero saber dela. Relatar o fato é uma consequência se ela vai relatar ou não. (...) eu acho que precisa se trabalhar essa questão da, da... do próprio atendimento às pessoas (Açucena)
\end{abstract}

Trabalhar essas questões relacionadas ao sofrimento psíquico também é ação que promove quebra de paradigma para essas psicólogas entrevistadas:

(...) é, nossa profissão ela trabalha muito isso. Ela trabalha muito quebra de paradigmas. E aí, assim, a gente tem que aprender a conviver com o outro mesmo. Ver o que esse outro deseja, ver o quê que esse outro quer. (Xena)

Diante desses resultados, pode-se pensar que a articulação entre os pressupostos psicanalíticos (Khel, 2008; Menezes, 2012; Laurent, 2012) e estudos de gênero (Butler, 1990; Swain, 2006; Arán, 2009; Lago, n.d.) pode ser uma possibilidade de referencial teórico para a intervenção psicológica junto às mulheres em situação de violência, mais especificamente, para as que permanecem nesta situação, mesmo com condições objetivas de rompimento .

A partir do que discute Khel (2008) e Menezes (2012), a estratégia utilizada para retomar esse amor, que na verdade seria conseguir sentir-se protegida de seu desamparo, é se degradando, se submetendo à violência e ao desprezo, como é reforçado a partir do dispositivo amoroso (Swain, 2006).

Um desespero que levaria algumas mulheres a considerar a dor da sujeição como mais possível de lidar do que com o vazio do desamparo. Essa ideia se articula com a concepção de dispositivo amoroso que institui a imagem do que é ser mulher e do que é preciso fazer para sê-la "doce, amável, devotada (incapaz, fútil, irracional, todas iguais!) e, sobretudo, amorosa. Amorosa com seu marido, seus filhos, sua família, além de todo limite, de toda expressão de si" (Swain, 2006, p. 10). Sendo o amor seu fundamento identitário, sua razão de viver e ser, que também podem ser entendidos como forma de lidar com o desamparo. 


\section{Considerações Finais}

Os resultados obtidos apontam no sentido de confirmação de estudos anteriores (Cunha, 2007; Porto \&Bucher-Maluschke, 2012) que indicam as dependências financeira e emocional como a motivação de algumas mulheres permanecerem em situação de violência, questões constitutivas das relações de gênero que trazem para a mulher a responsabilidade de manutenção do casamento e, nesse contexto, uma referência importante que se destaca é a ideia do amor romântico.

As categorias identificadas e que se inter-relacionam, apontam, a partir do que entendem as psicólogas entrevistadas, que há uma busca de realizar um desejo de viver a promessa do amor romântico, a plenitude possibilitada pelo encontro da metade que promoverá a completude, e para tal lutam para que ocorra a mudança do outro, pois temem as consequências de mudar seu desejo, ou melhor, enfrentar que esse desejo não poderá ser realizado. Ao mesmo tempo são sutil e cotidianamente confrontadas com modelos e referências constituídas no discurso sobre o feminino que enreda e constrói o que se é, o que faz e pensa ser, sem que nem se aperceba o que ocorre: o controle sobre seus corpos e desejos.

Por fim, é importante destacar que mais da metade das psicólogas entrevistadas têm como referência teórica a psicanálise, demonstrando que o entendimento das questões da subjetividade não são minimizadas ao funcionamento individual separado dos fenômenos sociais, como geralmente são as críticas dirigidas às ações da psicologia nas políticas públicas. Os resultados apontam que mesmo as psicólogas que têm na psicanálise seu referencial teórico, estas não avaliam a problemática de suas pacientes que sofrem violência do ponto de vista de um sofrimento pessoal, pelo contrário, entendem o fenômeno como algo produzido por uma construção social e cultural. Diferente do que aponta o estudo de Hanada et al. $(2008,2010)$, citado anteriormente. Também é importante frisar que os trechos destacados para ilustrar as categorias, em sua maioria, foram do grupo que não atendia na política pública especializada, ou seja, psicólogas que provavelmente não passaram por capacitações temáticas sobre gênero e violência contra as mulheres, como era esperado que tivesse ocorrido no grupo que trabalha nos serviços especializados.

Já os argumentos de ganhos secundários, masoquismo e dificuldade da mulher assumir sua responsabilidade na relação mediada pela violência - essa questão também identificada por Oliveira (2004) - parecem que são mesmo de psicólogas, que tentam entender o fenômeno da permanência nas relações mediadas pela violência a partir do funcionamento da subjetividade. O resultado do estudo ora apresentado, portanto, destaca que para as entrevistadas, considerar o funcionamento da subjetividade como elemento importante no estabelecimento da permanência nas situações de violência não significa negar o contexto social, histórico, cultural e político, pois entendem estes como sendo constitutivos e constituintes da subjetividade e do fenômeno citado. Isso é relevante na medida em que há uma ideia de que psicólogas não consideram os fenômenos sociais e assim atuam de forma a limitá-los ao aspecto psicológico, individualizado, desconsiderando o contexto cultural, histórico e social, ou seja, psicologizando o fenômeno social. As entrevistadas apontam que psicólogas mesmo aquelas que não estão na política especializada e/ ou referenciadas na teoria psicanalítica, consideram, e não poderia ser diferente, a subjetividade como o elemento no qual concentra suas ações, mas que essa subjetividade não pode se constituir fora da cultura.

A possibilidade de pensar sobre o conceito de gênero, a partir das teóricas citadas (da terceira onda[Lago, n. d.], como são conhecidas) articulado à teoria psicanalítica pode ser viável na tentativa de compreender o fenômeno da violência contra as mulheres, em especial, o que promove mulheres se manterem em situações de violência, mesmo quando teriam possibilidades sociais e econômicas de romper com estas. Todavia, parece ainda algo difícil de fazer. Contudo, essa interface apresenta-se promissora, mesmo que demande muito trabalho no desenvolvimento dessa articulação.

\section{Referências}

Arán, M. (2009). A psicanálise e o dispositivo diferença sexual. Revista Estudos Feministas, 17(3), 653-673.

Bardin, L. (1997). Análise de Conteúdo. Lisboa: Edições 70. (Trabalho original publicado em 1977)

Birman, J. (2006). Arquivos do mal-estar e da resistência. Rio de Janeiro: Civilização Brasileira.

Brandão, E. R. (1998). Violência conjugal e o recurso feminino à polícia. In C. Bruschini, \& H. B. Hollanda (Eds.), Horizontes plurais: novos estudos de gênero no Brasil (pp. 51-84). São Paulo: Editora 34/Fundação Carlos Chagas.

Brasil. Presidência da República, Secretaria Especial de Políticas para as Mulheres. (2003). Programa de Prevenção, Assistência e Combate à Violência Contra a Mulher - Plano Nacional: diálogos sobre violência doméstica e de gênero:construindo politicas públicas. Brasília: Autor.

Brasil. Presidência da República, Secretaria Especial de Políticas para as Mulheres. (2005a). Termo de Referência Casa-abrigo. Portaria no 003, de 24 de março. Brasília: Autor.

Brasil. Presidência da República, Secretaria Especial de Políticas para as Mulheres. (2005b). Termo de Referência. Centro de referência e atendimento à mulher. Portaria $\mathrm{n}^{\circ} 003$, de 24 de março. Brasília: Autor.

Brasil. Presidência da República, Secretaria Especial de Políticas para as Mulheres. (2006a). Termo de Referência. De 11 de janeiro. Brasília: Autor.

Brasil. Presidência da República, Secretaria Especial de Políticas para as Mulheres.(2006b). Norma Técnica de Uniformização: Centros de Referência de Atendimento à Mulher em Situação de Violência. Brasília: Autor.

Brasil, Presidência da República, Secretaria Especial de Políticas para as Mulheres. (2006c). Lei Maria da Penha: Lei $N^{\circ} 11.340$, de 7 de agosto de 2006. Coíbe a violência doméstica e familiar contra a mulher. Brasília: Autor. 
Butler, J. (1990). Gender trouble. Feminism and the Subversion of Identity. New York: Routledge.

Butler, J. (1992). Problema de los géneros, teoría feminista y discurso psicoanalítico. In J. L. Nicholson (Ed.), Feminismo/ posmodernismo (pp. 75-95). Buenos Aires: Feminaria Editora.

CFP - Conselho Federal de Psicologia (2008). Atuação de psicólogos em programas de atenção à mulher em situação de violência. (Relatório de pesquisa publicado no endereço eletrônico). Conselho Federal de Psicologia. - Brasília: CFP.

CFP - Conselho Federal de Psicologia. (2010). Práticas profissionais dos(as) psicólogos(as) nos programas de atenção às mulheres em situação de violência.Conselho Federal de Psicologia. Brasília: CFP.

Costa, J. F. (1998). Sem fraude nem favor. Rio de Janeiro: Rocco.

Cunha, T. R. A. (2007). O preço do silêncio: mulheres ricas também sofrem violencia. Vitória da Conquista: Uesb.

Foucault, M. (1988). A história da sexualidade I: a vontade de saber. In M. T. C.Albuquerque,\& J. A. G. Albuquerque, (Trans.). ( $7^{\mathrm{a}}$ ed.). Rio de Janeiro: Graal. (Trabalho original publicado em 1976)

Franco, M. L. P. B. (2008). Análise de Conteúdo (Vol. 6, 3ª ed.). (Série Pesquisa). Brasília: Líber Livro.

Freud, S. (2000). Esboço de Psicanálise. Edição Eletrônica Brasileira das Obras Psicológicas Completas de Sigmund Freud (Vol. 23). (Trabalho original publicado em 1938). CD-ROM.

Freud, S. (2000a). O Estranho. Edição Eletrônica Brasileira das Obras Psicológicas Completas de Sigmund Freud (Vol. 17). (Trabalho original publicado em1919). CD-ROM

Freud, S. (2000b). Uma criança é espancada - Uma contribuição ao estudo das origens das perversões sexuais. Edição Eletrônica Brasileira das Obras Psicológicas Completas de Sigmund Freud (Vol. 17). (Trabalho original publicado em 1919).CDROM.

Freud, S. (2000). Psicologia de grupo e a análise do ego. Edição Eletrônica Brasileira das Obras Psicológicas Completas de Sigmund Freud (Vol. 23).(Trabalho original publicado em 1921). CD-ROM.

Freud, S. (2000). Sobre o Narcisismo: uma introdução. Edição Eletrônica Brasileira das Obras Psicológicas Completas de Sigmund Freud (Vol. 14).(Trabalho original publicado em1914).CD-ROM.

Freud, S. (2007). O problema econômico do masoquismo. L. A. Hanns, (Ed. \& Trans.), Escritos sobre a psicologia do inconsciente (Vol. 3, pp.103-124). Rio de Janeiro: Imago. (Trabalho original publicado em 1924).

Freud, S. (2010). O mal-estar na cultura. R. Zwick, (Trans.), Porto Alegre: L\&PM. (Trabalho original publicado em 1930).
Garcia, M. V., Ribeiro, L. A., Jorge, M. T., Pereira, G. R., \& Resende,A. P. (2008). Caracterização dos casos de violência contra a mulher atendidos em três serviços na cidade de Uberlândia, Minas Gerais, Brasil. Cadernos de Saúde Pública, 24(11), 2551-2563.

Goldenberg, M. (2004). De perto ninguém é normal: estudo sobre corpo, sexualidade, gênero e desvio na cultura brasileira. Rio de Janeiro: Record.

Haddad, G. (2009). Amor e fidelidade. (Coleção Clínica Psicanalítica). São Paulo: Casa do Psicólogo.

Hanada, H., D’Oliveira, A. F. P. L.,\& Schraiber, L. B. (2010). Os psicólogos na rede de assistência a mulheres em situação de violência. Revista de Estudos Feministas, 18(1), 33-60.

Hanada, H., D’Oliveira, A. F. P. L., \& Schraiber, L. B. (2008, agosto). Os psicólogos e a assistência a mulheres em situação de violência. Seminário Internacional Fazendo Gênero 8: Corpo, Violência e Poder. Florianópolis, SC.

Kehl, M. R. (2008). Deslocamentos do feminino ( $2^{\mathrm{a}}$ ed.). Rio de Janeiro: Imago.

Lago,M. C. S. (n.d.).A Psicanálise nas Ondas dos Feminismos. Retrieved from http://www.miriamgrossi.cfh.prof.ufsc.br/ pdf/a_psicanalise_nas_ondas.pdf

Laurent, E. (2012). A psicanálise e as escolha das mulheres. Belo Horizonte: Scriptum Livros.

Menezes, L. S.(2012). Desamparo. (Coleção Clínica Psicanalítica). São Paulo: Casa do Psicólogo.

Narvaz, M. G. (2010). Masoquismo feminino e violência doméstica: reflexões para a clínica e para o ensino da psicologia. Psicologia Ensino \& Formação, 1(2), 47-59.

Oliveira, K. L. C. (2004). Quem tiver a garganta maior vai engolir o outro: sobre violências conjugais contemporâneas. São Paulo: Casa do Psicólogo.

Pinto, C. R. J. (2003). Uma história do feminismo no Brasil. São Paulo: Editora Fundação Perseu Abramo.

Porto, M., \& Bucher-Maluschke, J. S. N. F. (2012). Violência, mulheres e atendimento psicológico na Amazônia e Distrito Federal. Psicologia em Estudo (Maringá), 17(2), 297-306.

Swain, T. N. (2006). Entre a vida e a morte, o sexo (également en français). Labrys Études Féministes. Retrieved from: http:// www.intervencoesfeministas.mpbnet.com.br/textos/taniaentre_a_vida_ea_morte.pdf

Recebido em 30.04.2013

Primeira decisão editorial em 04.12.2013

Versão final em 28.02.2014

Aceito em 06.03.2014 